\title{
Bioengineering Functional Copolymers. XVII. Interaction of Organoboron Amide-Ester Branched Derivatives of Poly(Acrylic Acid) with Cancer Cells
}

\author{
Mustafa Türk ${ }^{1}$, Gülten Kahraman², Sevda A. Khalilova ${ }^{3}$,Zakir M. O. Rzayev", Serpil Oguztüzün ${ }^{1}$ \\ ${ }^{1}$ Department of Biology, Faculty of Arts and Sciences, Kırıkkale University, Yahşihan, Turkey; ${ }^{2}$ Sarayköy Nuclear Research and \\ Training Center, Turkish Atomic Energy Authority, Ankara, Turkey; ${ }^{3}$ Scientific Research Institute of Medicinal Prophylaxis, Minis- \\ try of Public Health, Baku, Azerbaijan; ${ }^{4}$ Institute of Science \& Engineering, Division of Nanoscience and Nanomedicine, Hacettepe \\ University, Ankara, Turkey. \\ Email: zmo@hacettepe.edu.tr
}

Received January $11^{\text {th }}, 2011$; revised May 20 $0^{\text {th }}, 2011$; accepted May 30 2011.

\begin{abstract}
Novel bioengineering functional organoboron polymers were synthesized by 1) amidolysis of poly(acrcylic acid) $(P A A)$ with 2-aminoethyldiphenyl borinate $(2-A E P B), 2)$ esterification of organoboron PAA polymer $(P A A-B)$ with $\alpha$-hydroxy- $\omega$-methoxypoly(ethylene oxide) (PEO) as a compatibilizer and 3) conjugation of organoboron PEO branches (PAA-B-PEO) with folic acid (FA) as a targeting agent. Structure and composition of the synthesized polymers were characterized by FTIR-ATR and ${ }^{1} H\left({ }^{13} \mathrm{C}\right)$ NMR spectroscopy, chemical and physical analysis methods. Antitumor activity of organoboron functional polymer and its complex with FA (PAA-B-PEO-F) against cancer and normal cells were evaluated by using different biochemical methods such as cytotoxicity, statistical, apoptotic and necrotic cell indexes, double staining and caspase-3 immune staining, light and fluorescence inverted microscope analyses. It was found that citotoxicity and apoptotic/necrotic effects of polymers significantly depend on the structure and composition of studied polymers, and increase the following raw: $P A A<<P A A-B<P A A-B-P E O<P A A-B-P E O-F$. Among them, $P A A-B-P E O-F$ complex at $400 \mu \mathrm{g} \cdot \mathrm{mL}^{-1}$ concentration as a therapeutic drug exhibits minimal toxicity toward the normal cells, but influential for HeLa cancer cells.
\end{abstract}

Keywords: Synthesis, Amidolysis, Organoboron Polymers, Conjugation, Citotoxicity, Apoptotic and Necrotic Effects

\section{Introduction}

Many natural polymers such as polylysine, polyarginine, dextran derivatives, heparin and chitosan, and synthetic bioengineering polymers such as poly(acrylic acid) (PAA), copolymers of maleic anhydride, have now been reported to have direct or indirect antitumor activity via stimulation of the immune system [1-3]. In recent years, the PAA and its copolymers have been often used as carriers in drug release systems, because of their multifunctional nature, unique properties and good biocompatibility [4,5]. Dimitrov et al. [5] studied the biopharmaceutical characterization of hydrogels based on crosslinked

\footnotetext{
"Sponsors: TUBITAK (Turkish Scientific and Technological Research Council) and TAEK (Turkish Atomic Energy Authority).
}

PAA and showed that this studied systems provide retarded drug release and appear to be potential candidates for use in the pharmaceutical practice. PAA is grafted to the poly(ethylene glycol) hydro-gel by photo-induced graft polymerization. Due to carboxyl functionality of PAA, collagen and cell adhesion protein, they could be covalently immobilized on to the poly(ethylene glycol) hydrogel [6]. Most of the hydrogels utilized as adhesives for dermatological patches were composed using PAA and its salts as matrix polymers. The ionic interactions between the carboxyl groups of the polymer and polyvalent cations such as calcium, copper, and aluminum cause the formation of the chemical crosslinking used to increase their mechanical strengths [7].

Acrylate-based polymers, containing carboxylic groups, 
exhibit a swelling behaviour depending on $\mathrm{pH}$ and ionic strength of solution [8,9]. Argentiere et al. [10] investigated PAA nanogels as $\mathrm{pH}$-sensitive carriers for biomedical applications. They prepared PAA-biopolymer nanogels by loading and release of an oligothiophene fluorophore and its albumin conjugate onto the PAA macromolecules.

On the other hand, several synthetic boron-containing compounds exhibiting important biological properties were investigated as potential therapeutics $[11,12]$. The mild electrophilic nature of the boronic acid moiety has led to its use at the 'warhead' site of enzyme inhibitors, particularly for inhibiting proteases. For this purposes, several researchers developed some $\alpha$-aminoboronic acid derivatives $[11,13]$. One such compound, the novel proteasome inhibitor bortezomib (Velcade) has been recently approved for clinical use as an anticancer agent for the treatment of myeloma [14].

Ban et al. [15] synthesized a series of $o$-carboranyl phenoxy derivatives as potent inducers for the activation of the $20 \mathrm{~S}$ proteasome and as chemical probes for the investigation of proteasome-dependent degradation pathways. Other types of bioactive boron-containing compounds have been investigation as therapeutic agents. These include certain boron analogues of biomolecules [16], diazaborine as an antibacterial and antimalarial agent [17], various antibacterial oxazaborolidines [18], the antibacterial diphenyl borinic esters to inhibit bacterial cell wall growth [19], the antifungal agent benzoxaborole (AN2690) [20], and an oestrogen receptor modulator containing a B-N bond [21].

Some organoboron compounds, including boronic acids and its functional derivatives, and carboranes, were also investigated as agents for boron-neutron capture therapy $(\mathrm{BCNT})$ for the treatment of brain tumors $[12,22$, 23].

The goal of this work is synthesis and characterization of novel organoboron amide-ester derivatives by amidolysis of PAA with 2-aminoethyldiphenyl borinate (2-AEPB) and their $\alpha, \omega$-hydroxy-methoxypoly(ethylene oxide) (PEO) macrobranched derivative by grafting of synthesized organoboron polymer with PEO to improve the biocompatibility and degree of conjugation with cancer biomacromolecules. An important aspect of this work is comparative investigations of the interactions of these novel functionalized organoboron polymers with $\mathrm{HeLa}$ (human cervix carcinoma cell) cancer cells and L929 Fibroblast normal cells, and evaluation of their antitumor activity (cytotoxicity, apoptotic and necrotic effects) using various biochemical methods such as hematoxylen/eosin and immune cytochemical staining, light and fluorescence inverted microscopy analyses.
Synthetic partway of the side-chain amide-, ester- and carboxyl-functionalized organoboron polymers can be represented as follows (Scheme 1).

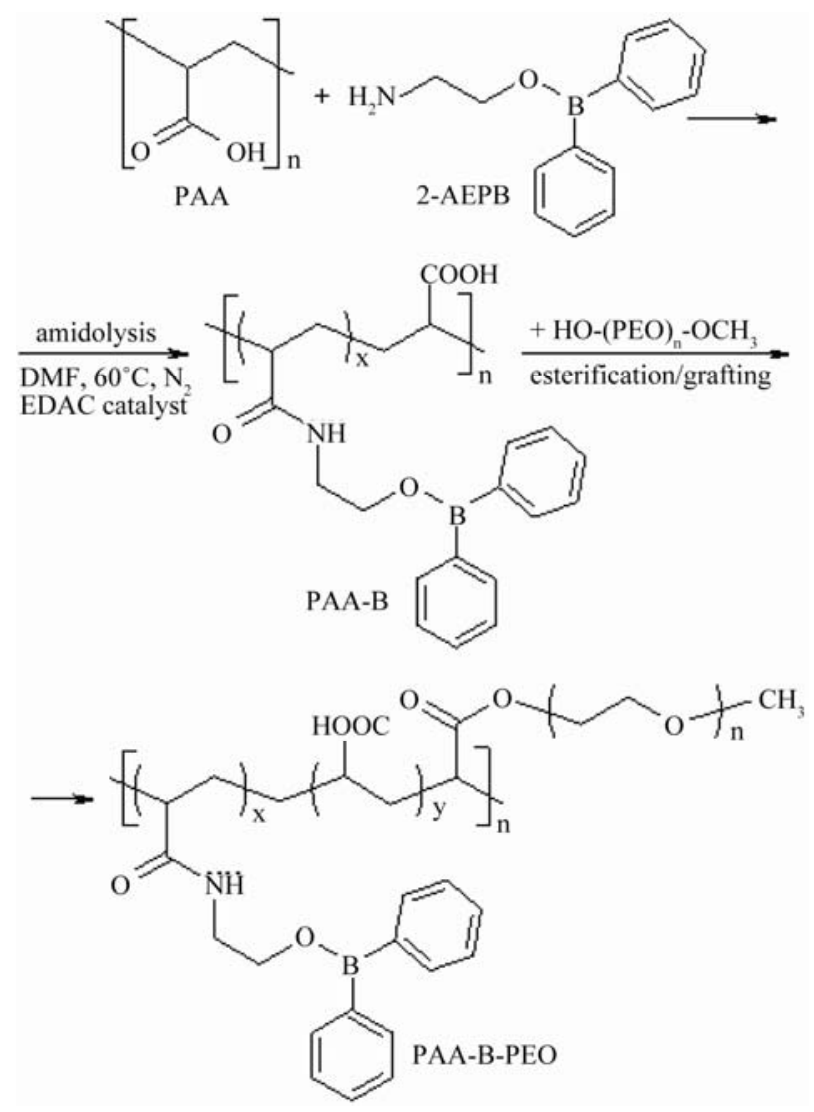

Scheme 1. Synthetic partway of the organoboron amideester-carboxyl functionalized polymers via amidolysis and esterification/grafting reactions.

\section{Experimental}

\subsection{Materials}

PAA (BDH) was used as $25 \%$ aqueous solution with $M_{\mathrm{w}}$ $230.000 \mathrm{~g} / \mathrm{mol}$ and density $1.09 \mathrm{~g} / \mathrm{ml}$. 2-Aminoethyl diphenylborinate (2-AEPB) (Sigma-Aldrich, Germany) was purified by recrystallization from anhydrous ethanol: m.p. $193.5^{\circ} \mathrm{C}$ (by DSC); FTIR-ATR spectra of 2-AEPB, $\mathrm{cm}^{-1}: 3284$ (vs) and 3220 (s) $\mathrm{N}-\mathrm{H}$ stretching in $\mathrm{NH}_{2}$, 3066 (vs)-2870(s) C-H stretching, 1611(vs) $\mathrm{NH}_{2}$ bending and $\mathrm{C}=\mathrm{C}$ stretching in phenyl groups, $1491(\mathrm{~m})$ and 1334 (m) B-O band, 1432 (vs) fairly strong, sharp band due to benzene ring vibration in phenyl-boronic acid linkage, 1263-1154 (s) fairly strong, sharp bands due to C-N stretching in $\mathrm{C}-\mathrm{NH}_{2}, 1061$ (vs) $\mathrm{N}-\mathrm{H}$ bending in $\mathrm{NH}_{2}$ and 750-710(s) sharp bands due to boron-phenyl linkage; ${ }^{1} \mathrm{H}$ NMR spectra $(\delta$, ppm $)$ in $\mathrm{CHCl}_{3}-\mathrm{d}_{1}: \mathrm{CH}_{2}-\mathrm{O} 1.49$, 
$\mathrm{CH}_{2}-\mathrm{NH}_{2}$ 2.96, and 7.38-7.40 (1H), 7.19-7.24 (2H) and 7.13-7.16 $(2 \mathrm{H})$ for protons of $p$-, $o$ - and $m$-positions in benzene ring, respectively.

$\alpha$-Hydroxy- $\omega$-methoxy-PEO $\left(M_{\mathrm{n}} 2000 \mathrm{~g} \cdot \mathrm{mol}^{-1}\right)$ (Fluka). ${ }^{1} \mathrm{H}$ NMR spectra $(\delta, \mathrm{ppm})$ in $\mathrm{CHCl}_{3}-d_{1}$ : $\mathrm{CH}_{2}-\mathrm{O} 3.75-3.45$, $\mathrm{OH}$ end group 2.61 and $\mathrm{O}-\mathrm{CH}_{3}$ end group 2.16.

$N$-Ethyl- $N$-(3-dimethylaminopropyl)carbodiimide hydrochloride (EDAC) as a catalyst and folic acid (FA) as a targeting agent were supported from Aldrich-Sigma (Germany). All solvents and reagents were of analytical grade and used without purification

HeLa (human cervix carcinoma cell) cancer cells and L929 Fibroblast cells were obtained from the tissue culture collection of the SAP Institute (Ankara, Turkey). Cell culture flasks and other plastic material were purchased from Corning (NY, USA). The growth medium, which is Dulbecco Modified Medium (DMEM) without L-glutamine supplemented fetal calf serum (FCS), and Trypsin-EDTA were purchased from Biological Industries (Kibbutz Beit Haemek, Israel). The primary antibody, caspase-3 was purchased from Lab Vision (Germany).

\subsection{Synthesis of 2-Amidoethyldiphenylborinate-poly(Acrylic Acid)}

Amidolysis of PAA with 2-AEPB using various [PAA]/[2-AEPB] mole ratios was carried out in $N, N^{\prime}$-dimethylformamide (DMF) at $60^{\circ} \mathrm{C}$ with EDAC catalyst under the nitrogen atmosphere using a standard Pyrex-glass reactor supplied by a mixer, temperature control unit and condenser. Reaction conditions: $[2-\mathrm{AEPB}]=$ $0.066 \mathrm{~mol} \cdot \mathrm{L}^{-1}$, mole ratios of $[\mathrm{PAA}] /[2-\mathrm{AEPB}]=1: 1$, 3: $1,5: 1$ and $\mathrm{EDAC}=1.0 \mathrm{wt} \%$. Appropriate quantities of PAA, 2-AEPB, DMF and EDAC were placed in a reactor and the reaction mixture was flushed with dried nitrogen gas for at least $2 \mathrm{~min}$, then sealed and placed in a thermo stated silicon oil bath at $60^{\circ} \mathrm{C}$ to intensive mixing for $5 \mathrm{~h}$. The organoboron amide polymer was isolated from reaction mixture by precipitation with diethyl ether and dried under vacuum. Synthesized organoboron polymer has the following average parameters: $T_{\mathrm{g}}$ (by DSC) $190.6^{\circ} \mathrm{C},[\eta]_{\text {in }}$ in deionized water at $25^{\circ} \mathrm{C} 2.72 \mathrm{dL} \cdot \mathrm{g}^{-1}$; FTIR-ATR spectra of PAA-g-2-AEPB (KBr pellet), $\mathrm{cm}^{-1}: 1702(\mathrm{~m}) \mathrm{C}=\mathrm{O}$ stretching (amide I band), $1642(\mathrm{w})$ and $1542(\mathrm{~m}) \mathrm{N}-\mathrm{H}$ deformation (amide II band), 1446(m) and 1407(w) C-N stretching (amide III band); ${ }^{1} \mathrm{H}$ NMR spectra (in DMSO- $\mathrm{d}_{6}$ at $25^{\circ} \mathrm{C}$ ) $\delta$ ppm: protons of phenyl groups $7.9,2 \mathrm{H}$ from $\mathrm{CH}_{2}$ in $-\mathrm{CH}_{2}$-CO-NH- fragment 7.3, $2 \mathrm{H}$ from $\mathrm{B}-\mathrm{O}-\mathrm{CH}_{2}$ group 3.6, $2 \mathrm{H}$ from $\mathrm{NH}-\mathrm{CH}_{2}$ group 3.0 and $2 \mathrm{H}$ from backbone -CH-CH- 3.3, 2.2 and $1.2-1.7 ;{ }^{13} \mathrm{C}$ NMR spectra $(\delta$ ppm):
$\mathrm{C}=\mathrm{O}$ of PAA unit/amide linkage $177, \mathrm{CH}=$ in phenyl groups 162-158, backbone $\mathrm{CH}_{2}$ and $\mathrm{CH} 128-127$ and 57, NH- $\mathrm{CH}_{2} 41-42, \mathrm{CH}_{2}-\mathrm{O} 31-36$.

\subsection{Synthesis of PEO Branched Organboron Copolymer}

The esterification (grafting) of organoboron amide of PAA, containing $19.24 \mathrm{~mol} \%$ of organoboron groups, with PEO $\left(M_{\mathrm{n}} 2000 \mathrm{~g} \cdot \mathrm{mol}^{-1}\right)$ at organoboron polymer/PEO feed molar ratio 1: 0.01 was carried out in DMF at $60^{\circ} \mathrm{C}$ for $1 \mathrm{~h}$. PEO branched polymer was isolated from reaction mixture by precipitation with diethyl ether and dried $40^{\circ} \mathrm{C}$ under vacuum. Prepared PEO ester of organoboron polymer has the following average characteristics: $T_{\mathrm{g}} 175.8^{\circ} \mathrm{C}$ (by DSC); $[\eta]_{\text {in }}$ in deionized water at $25^{\circ} \mathrm{C} 0.9 \mathrm{dL} \cdot \mathrm{g}^{-1} ;{ }^{1} \mathrm{H}$ NMR spectra (in DMSO- $d_{6}$ at $\left.25^{\circ} \mathrm{C}\right) \delta$ ppm: protons of phenyl groups $7.8, \mathrm{CH}_{2}$ in $\mathrm{CH}_{2}$-CO-NH- amide group $7.2,2 \mathrm{H}$ in $\mathrm{B}-\mathrm{O}-\mathrm{CH}_{2} 3.5$, $\mathrm{CH}_{2} \mathrm{CH}_{2}$ in PEO branch $3.35,3 \mathrm{H}$ in $\mathrm{OCH}_{3}$ end group 3.1 and $2 \mathrm{H}$ in $\mathrm{NH}-\mathrm{CH}_{2} 2.9 ;{ }^{13} \mathrm{C}$ NMR spectra $(\delta \mathrm{ppm}): \mathrm{C}=\mathrm{O}$ in $-\mathrm{COOH} 176, \mathrm{CH}=$ in phenyl groups 162 , backbone $\mathrm{CH}_{2}$ and $\mathrm{CH} 128$ and 127, respectively, $\mathrm{O}-\mathrm{CH}_{2}$ in PEO 69, end $\mathrm{OCH}_{3}$ group of PEO 57, NH-CH 2 41-42, and $\mathrm{CH}_{2}$-O-B 31-36.

\subsection{Characterization}

Fourier transform infrared (FTIR-ATR) spectra were recorded with FTIR Nicolet 8700 spectrometer in the $3700-600 \mathrm{~cm}^{-1}$ range. ${ }^{1} \mathrm{H}$ and ${ }^{13} \mathrm{C}$ NMR spectra were performed on a Bruker Avance (300 MHz) spectrometer with DMSO- $\mathrm{d}_{6}$ as a solvent at $25^{\circ} \mathrm{C}$. Thermo gravimetric (TGA) and differential scanning calorimetric (DSC) analyses were performed in a TGA-DTA (Perkin Elmer TG/DTA6300) and a DSC2010 Thermal Analyzers, respectively, under nitrogen atmosphere at a heating rate of $10^{\circ} \mathrm{C} / \mathrm{min}$. The intrinsic viscosity $[\eta]_{\text {in }}$ values of the organoboron polymers were determined in deionized water at $25^{\circ} \mathrm{C} \pm 0.1^{\circ} \mathrm{C}$ in the concentration range $0.003-0.06$ $\mathrm{g} \cdot \mathrm{dL}^{-1}$ using an Ubbelohde viscometer.

Analyses of cytotoxicity, apoptotic and necrotic cells with double staining and immune cytochemical stains of the synthesized novel organoboron functional polymers were performed according to the modified methods using in our recent published work $[25,26]$. For cytotoxicity experiments, HeLa and L 929 Fibroblast cells $\left(50 \times 10^{3}\right.$ cells per well) were placed in DMEM by using 24-well plates. Different amounts of pristine PPA and organoboron polymers (PAA-B, PPA-PEO-B and PAA-PEO-B-F) (about $0-650 \mu \mathrm{g} \cdot \mathrm{mL}^{-1}$ in aqueous solutions) were put into wells containing cells, respectively. The plates were kept in the $\mathrm{CO}_{2}$ incubator $\left(37^{\circ} \mathrm{C}\right.$ in $\left.5 \% \mathrm{CO}_{2}\right)$ for $24 \mathrm{~h}$; the medium was replaced with fresh medium, and incubated 
at the same conditions for $24 \mathrm{~h}$. Following of this incubation, HeLa cells were harvested with trypsin-EDTA, and then were dyed with trypan blue. The number of living and dead cells were counted with a haemacytometer (C.A. Hausse \& Son Phluila, USA), using light microscope at $\times 200$ magnification. Analysis of apoptotic and necrotic cells with double staining were performed to quantify the number of apoptotic cells in culture on basis of scoring of apoptotic cell nuclei. HeLa and L929 fibroblast cells $\left(20 \times 10^{3}\right.$ cells per well) were placed in DMEM by using 24 -well plates. After treating with different amount functional oligomers (about $0-650 \mu \mathrm{g} \cdot \mathrm{mL}^{-1}$ in aqueous solutions) for 24 hours period, both attached and detached cells were collected, then washed with PBS and stained with Hoechst dye $33342\left(2 \mu \mathrm{g} \cdot \mathrm{mL}^{-1}\right)$, propodium iodide (PI) $\left(1.0 \mu \mathrm{g} \cdot \mathrm{mL}^{-1}\right)$ and DNAse free-RNAse $\left(100 \mu \mathrm{g} \cdot \mathrm{mL}^{-1}\right)$ for $15 \mathrm{~min}$ at room temperature. After that $10-50 \mu \mathrm{L}$ of cell suspension was smeared on slide and cover slip for examination by fluorescence microscopy. The nuclei of normal cells were stained light blue but apoptotic cells were stained dark blue by the Hoechst dye.

The apoptotic cells were identified by their nuclear morphology as a nuclear fragmentation or chromatin condensation. Necrotic cells were staining red by PI. Necrotic cells lacking plasma membrane integrity and PI dye cross cell membrane, but PI dye don't cross non necrotic cell membrane. The number of apoptotic and necrotic cells in 10 randomly chosen microscopic fields were counted and the result expressed as a ratio of apoptotic and necrotic to normal cells. The number of apoptotic and necrotic cells were determined by light and fluorescence inverted microscope (Leica, Germany). The cell images were also recorded using the both above mentions microscopes with DAPI and FITC filters, respectively.

For immunocytochemical stains, about $2 \mathrm{ml} \mathrm{HeLa} \mathrm{(20}$ $\times 10^{3}$ cells per well), treated with functional oligomers (about $0-650 \mu \mathrm{g} \cdot \mathrm{mL}^{-1}$ in aqueous solutions) suspension was centrifuged for $5 \mathrm{~min}$ in a Hettich centrifuge. Cytospin preparations were fixed in $70 \%$ ethanol for immunocytochemistry.

For an indirect immunocytochemical procedure, cytology specimens were treated with $3 \% \mathrm{H}_{2} \mathrm{O}_{2}$ for $10 \mathrm{~min}$, taken to water, and then rinsed in PBS (pH 7.4) for $5 \mathrm{~min}$. Nonspecific protein binding was blocked on specimen by incubating with blocking solution for $10 \mathrm{~min}$. The primary antibody, caspase-3 (Lab Vision) used at 1:300 dilution, incubated for $1 \mathrm{~h}$ at room temperature. Specimens were washed with PBS buffer (pH 7.4) and incubated in biotinylated secondary antibody solution for 10 min. Diaminobenzidine (Dako) served as the chromagen and Mayer's hematoxylin as the counter stain. For the negative control the primary antibody was omitted in one of the slides.

The immunocytochemical staining results were controlled independent and blindly by observers without the knowledge of treatment. The immunoreactivity of the caspase-3 antibody is confined to the cytoplasm of apoptotic cells. We counted the number of caspase-3-positive cytoplasmic staining cells in all fields found at $\times 400$ final magnification. For each image, three randomly selected microscopic fields were observed, and at least of 100 cells/field were evaluated.

\section{Results and Discussion}

\subsection{Structure of Organoboron Polymers}

The structures of synthesized organoboron polymers and their PEO branches were confirmed by FTIR-ATR and ${ }^{1} \mathrm{H}$ $\left({ }^{13} \mathrm{C}\right) \mathrm{NMR}$ analysis. Comparative analysis of FTIR-ATR spectra (Figure 1) of 2-AEPB, PAA and its organoboron derivative indicates that the characteristic bands of acid $\mathrm{C}=\mathrm{O}$ groups disappearance in the spectra of PAA-B-1 polymer prepared from 1:1 molar feed ratio of PAA: 2-AEPB.

The formation of amide bound in this organoboron polymer is confirmed by the appearance of new bands such as 1702 (amide-I band), 1642 and 1542 (amide-II band), $1446 \mathrm{~cm}^{-1}$ and 1407 (amide-III band). Simultaneously a very broad band between 3500 and $2500 \mathrm{~cm}^{-1}$ appearances in spectra due to increase hydrogen bonded fragments in organoboron polymer (PAA-B-1). As the intensities of amide bands significantly decrease in spectra of PAA-B-2 and PAA-B-3 polymers prepared from

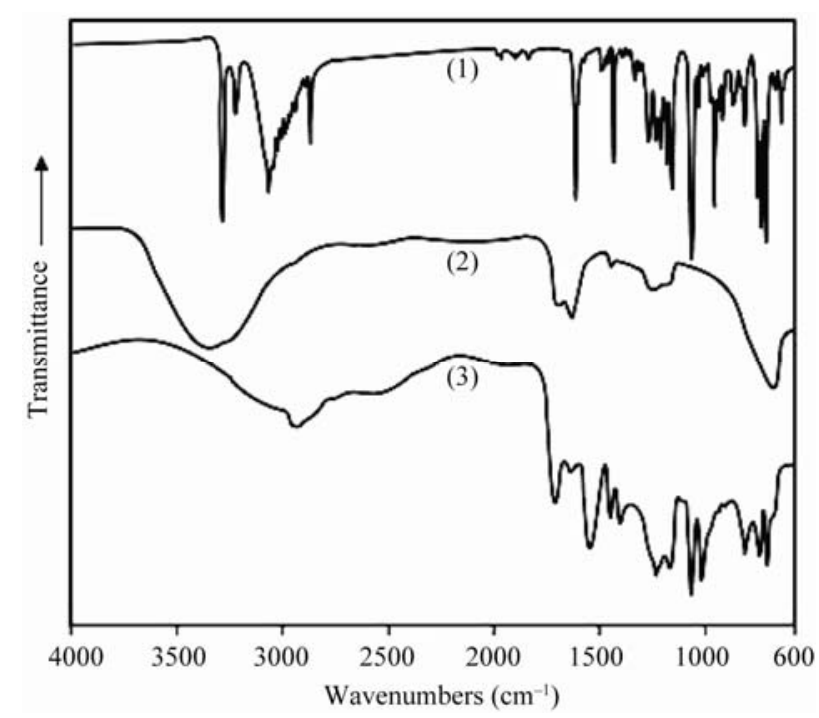

Figure 1. FTIR spectra: (1) 2-AEPB, (2) PAA and (3) PAAg-2-AEPB-1 organoboron amide polymer. 
$\mathrm{PAA} / 2$ 2-AEPB mixtures enchasing with PAA (PAA $>>$ 2-AEPB), the intensities of free acid group bands increase. Similar effect has been observed from comparative analysis of the ${ }^{1} \mathrm{H}$ and ${ }^{13} \mathrm{C}$ NMR spectra of A-B-2and its PEO branch (PAA-B-PEO). The results of this analysis are illustrated in Figures 2 and 3. The formation of $\mathrm{H}$-bonded amide linkages is confirmed by a presence of characteristic broad peaks at 7.3 and $177 \mathrm{ppm}$ in the ${ }^{1} \mathrm{H}$ and ${ }^{13} \mathrm{C}$ NMR spectra of PAA-B-2, respectively (Figure 2). In addition, the presence of characteristic proton peaks of organoboron linkages such as quarter phenyl peak at $7.9 \mathrm{ppm}$, triplet $\mathrm{B}-\mathrm{O}-\mathrm{CH}_{2}$ peak at $3.6 \mathrm{ppm}$ andquarter $\mathrm{NH}-\mathrm{CH}_{2}$ peak at $3.0 \mathrm{ppm}$ (Figure 2(a)) also confirmed that 2-AEPB is covalently bound to anhydride units. In the ${ }^{13} \mathrm{C}$ NMR spectra of PAA-B-2 polymer (Figure 2(b)), the characteristic carbon resonances (162, $158,41,42,31$ and $36 \mathrm{ppm}$ ) from organoboron fragment are also observed.

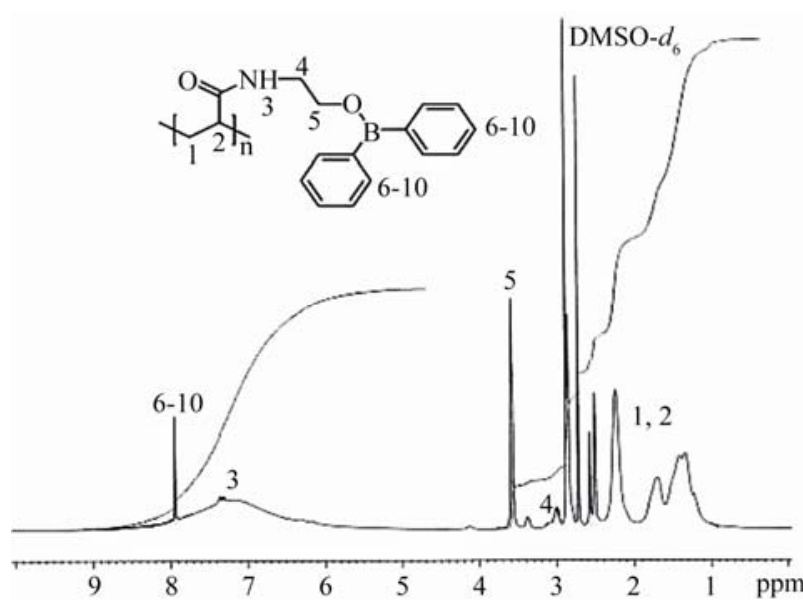

(a)

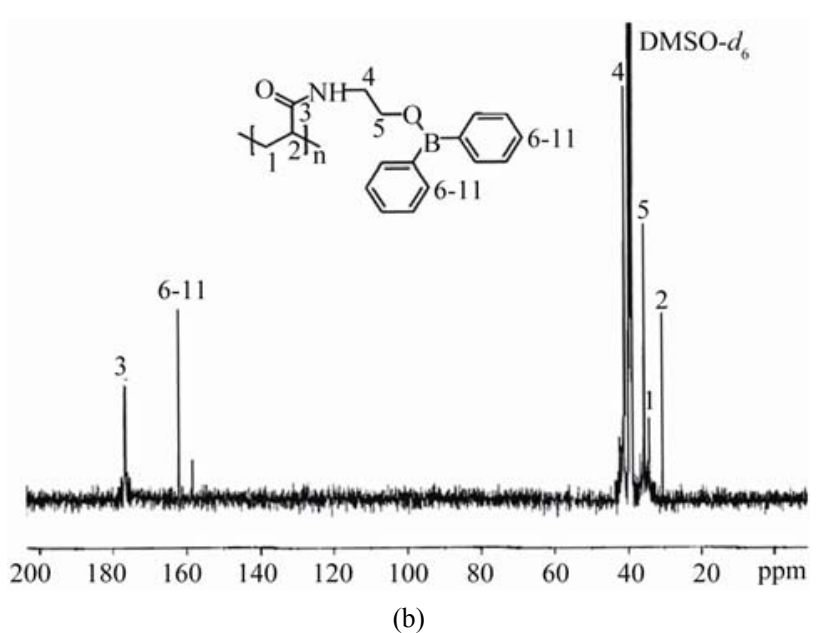

Figure 2. (a) ${ }^{1} \mathrm{H}$ NMR and (b) ${ }^{13} \mathrm{C}$ NMR spectra of organoboron polymer (PAA-B) in DMSO- $d_{6}$.

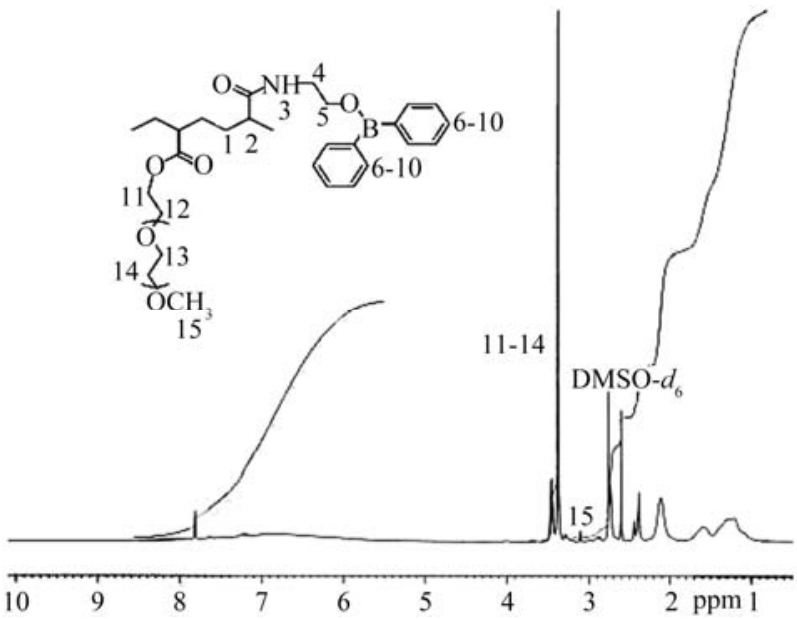

(a)

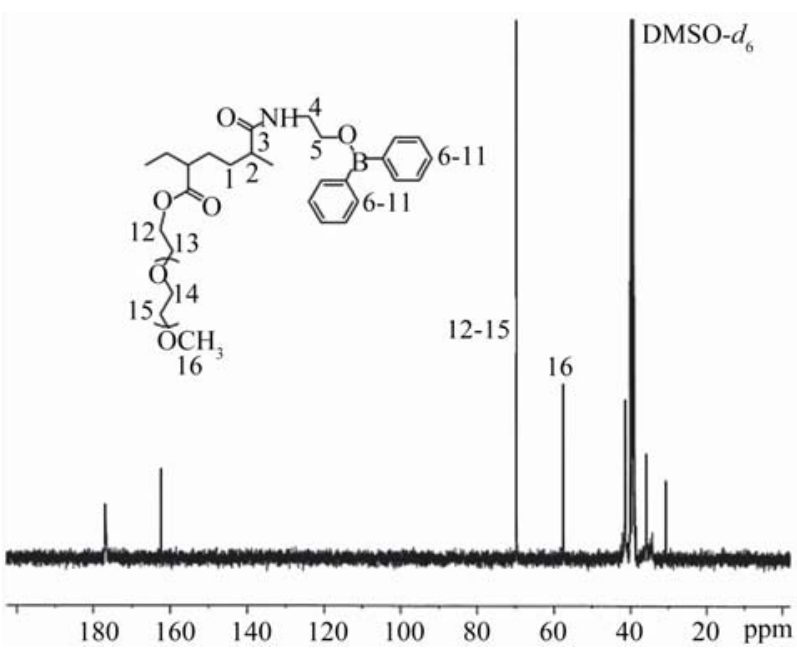

(b)

Figure 3. (a) ${ }^{1} \mathrm{H}$ NMR and (b) ${ }^{13} \mathrm{C}$ NMR spectra of PAA-gAEPB-2-g-PEO in DMSO- $d_{6}$.

${ }^{1} \mathrm{H}\left({ }^{13} \mathrm{C}\right)$ NMR spectra of PEO grafted organoboron PAA polymer (PAA-B-PEO) were illustrated in Figure 3. The observed proton signals from of side-chain PEO branches at 3.4 and $3.1 \mathrm{ppm}$ for $\left(\mathrm{CH}_{2}-\mathrm{CH}_{2}-\mathrm{O}\right)_{\mathrm{n}}$ units (Figure 3(a)) and carbon atom resonances $(69 \mathrm{ppm}$ for $\mathrm{O}-\mathrm{CH}_{2}$ and $57 \mathrm{ppm}$ for $\mathrm{OCH}_{3}$ end group) (Figure 3(b)) may be served an additional fact to confirm the formation of side-chain macrobranched PEO linkages.

\subsection{Functional Polymer Composition-Property Relationship}

The results of intrinsic viscosity measurements from the plots of $\eta_{\mathrm{sp}} \mathcal{c}$ (specific viscosity) vs. $c$ (polymer concentration in deionized water) for the organoboron PAA and PEO derivatives having different compositions are illustrated in Figure 4. A visible decrease of $\eta_{\text {in }}$ value with 


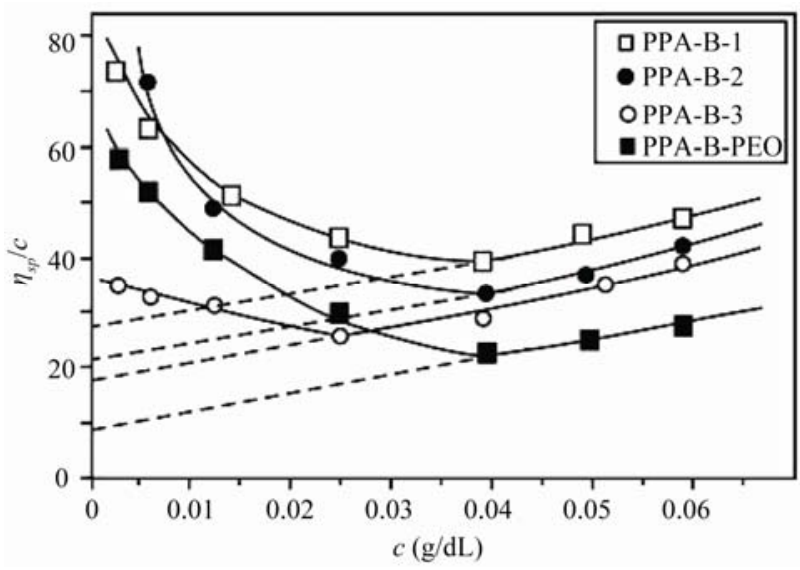

Figure 4. The plots of $\eta_{\mathrm{sp}} / c$ (specific viscoity) versus $c$ (polymer concentrations in deionized water) for the determination of intrinsic viscosity and evaluation of polymer composition-viscosity relationships (dilution effect and polyelectrolyte behaviour): - $\square-$ PPA-B-1, - - PPA-B-2, - oPAA-B-3 and -- PAA-B-PEO.

Table 1. Some characteristic parameters of organoboron amide (PAA-B) and PEO branched (PAA-B-PEO) derivatives of PAA.

\begin{tabular}{lccc}
\hline $\begin{array}{l}\text { Functional } \\
\text { polymers }\end{array}$ & $\begin{array}{c}\mathrm{B} \text { content } \\
(\%)\end{array}$ & $\begin{array}{c}{[\eta]_{\text {in }}\left(\mathrm{dL} \cdot \mathrm{g}^{-1}\right)} \\
\text { in water at } 25^{\circ} \mathrm{C}\end{array}$ & $\begin{array}{c}T_{g} \\
\left({ }^{\circ} \mathrm{C}\right)\end{array}$ \\
\hline PAA-B-1 & 3.64 & 2.75 & 190.6 \\
PAA-B-2 & 2.45 & 2.16 & 185.0 \\
PAA-B-3 & 1.85 & 1.74 & 181.2 \\
PAA-B-2-PEO & 2.16 & 0.85 & 175.8 \\
\hline
\end{tabular}

increasing the organoboron fragment in PAA polymer was observed (Table 1). Unlike the PEO branched derivative the organoboron polymers exhibit typical polyelectrolyte behavior, i.e., increase in viscosity with a dilution of polymer water solution, which can be explained by specific behavior of complexed macromolecules and their conformational changes resulting in the expansion of polymer coil in the dilution solution. Similar effect was observed for the other carboxyl-containing polymers $[27,28]$.

Thermal behavior and phase transitons of synthesized organoboron polymers were investigated by differential scanning calorimetric (DSC) and thermal gravimetrical analysis (TGA) methods. The obtained results were summarized in Figure 5. It was found that PAA and its organoboron and PEO branched derivatives exhibit amorphous structure with characteristically broad endo-peaks, which are associated with the glass-transition temperatures $\left(T_{g}\right)$, significantly depend on the composition and content of organoboron linkages in the functional polymers. The higher values of $T_{g}$ are observed for the polymers containing relatively high organoboron linkages.

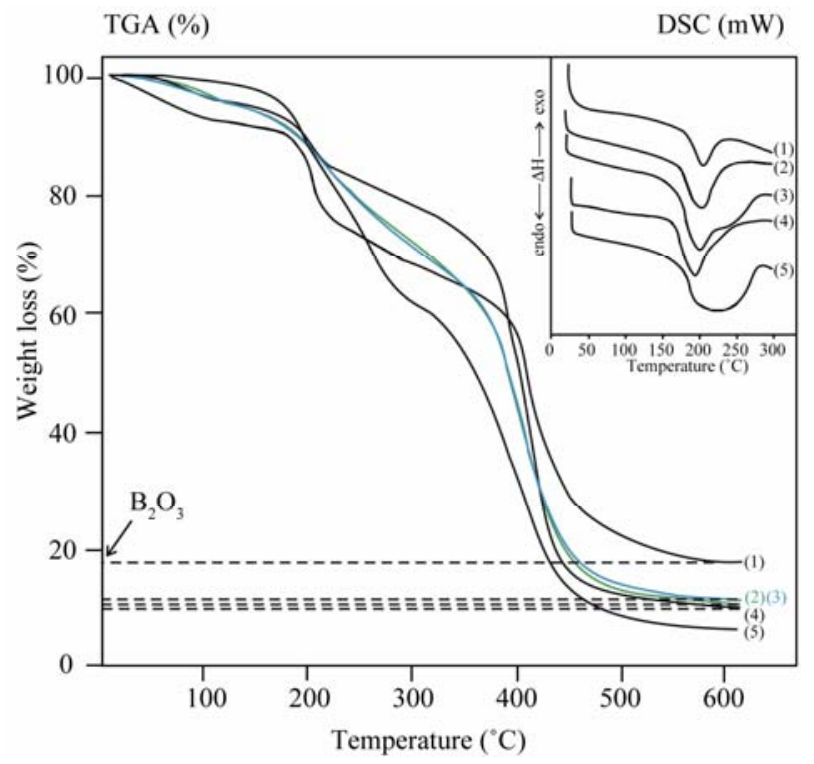

Figure 5. DSC and TGA curves of functional organoboron polymers: (1) PAA-B-1, (2) PAA-B-2, (3) PAA-B-3, (4) PAA-B-PEO and (5) pristine PAA. Heating rate $10^{\circ} \mathrm{C} / \mathrm{min}$ under a nitrogen atmosphere.

Therefore, rigid H-bonded structure provides high $T_{g}$ in the organoboron polymers (curves 1-3). The results of TGA analyses (Figure 5) indicate that the organoboron polymer and PEO branched derivative of PAA show higher thermal stability which increases with increasing degree of grafted organoboron linkage in the polymer. The observed two step degradation of the PAA and its functionalized derivatives indicates occurrence of some macromolecular reactions. TGA analyses also allow us to determine the content of boron in studied functionalized polymers, results of which are summarized in Table 1.

\subsection{Cytotoxicity}

The obtained cytotoxicity results of the pristine PAA and its organoboron amide (PAA-B) and organoboron amide-ester (PAA-B-PEO) branches, and PAA-B- PEO/ folic acid complex (PAA-B-PEO-F) on cancer cells using a trypan blue staining were illustrated in Figure 6. As seen from plots of concentration of polymers versus percent of cell viability, the toxicity of pristine PAA against cancer and normal cells decreased with an increasing in polymer concentration from 100 to $200 \mu \mathrm{g} \cdot \mathrm{mL}^{-1}$ for $24 \mathrm{~h}$ incubation at $37^{\circ} \mathrm{C}$. If polymer concentration was higher than 20 $\mu \mathrm{g} \cdot \mathrm{mL}^{-1}$, its toxicity increased, especially higher toxicity exhibits for $24 \mathrm{~h}$ incubation. The toxicity of PAA-B (organoboron amide polymer) was more significant than other polymer systems.

Figure 6 shows that the number of viable cells is above $80 \%$ for normal and cancer cells after incubation 


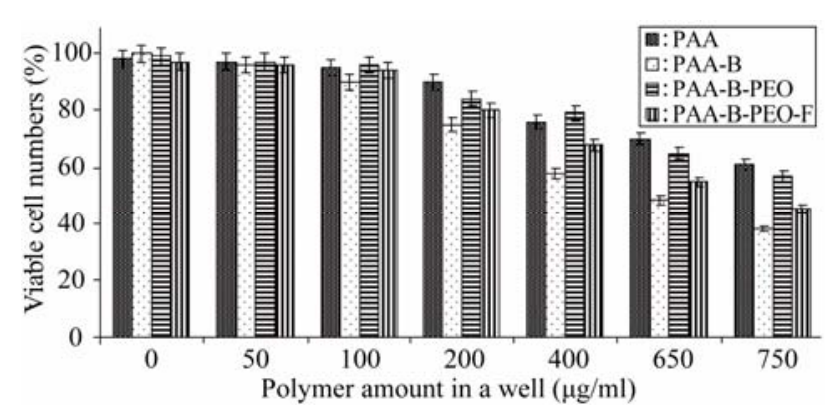

Figure 6. In vitro cytotoxicity of pristine PAA and functionalized organoboron polymers with different amounts at 24 $h$ incubation. Results are presented as means \pm SEM.

of the cells with PAA-B at concentrations around 100 $200 \mu \mathrm{g} \cdot \mathrm{mL}^{-1}$ for $24 \mathrm{~h}$ incubating time in cell culture media. The number of viable cells was over $50 \%$ or normal cells in the range of $400-650 \mu \mathrm{g} \cdot \mathrm{mL}^{-1}$ concentration. However, the toxicity of cancer cells was increased beginning from $400 \mu \mathrm{g} \cdot \mathrm{mL}^{-1}$.

The PAA-B and PAA-B-PEO-F polymers had higher toxicity for cancer cells (55\% alive cells) than normal cells $\left(68 \%\right.$ alive cells) in $650 \mu \mathrm{g} \cdot \mathrm{mL}^{-1}$ concentration of polymer...FA complex. It was observed that the cytotoxicity of PAA-B-PEO decreases as compared with organoboron polymers, which can be explained by compatibilizing effect of PEO branched linkages. The cytotoxicity of PEO containing polymer was lower than those without PEO at $400-650 \mu \mathrm{g} \cdot \mathrm{mL}^{-1}$ concentration (Figure 6). To improve the targeting of polymer macromolecules to cancer cells, folic acid (FA) was inserted to the structure through complex-formation.

The formation of organoboron polymer...FA complex through interaction of amide or carboxylic groups with pseudo-aromatic amine of FA and its conjugation with HeLa cells may be schematically represented as follows (Scheme 2).

When the polymer...FA complex was incubated, the toxicity of the HeLa cells was higher than that of the normal cells, because cancer cells had more FA receptors than normal cells. Therefore PAA-B-PEO-F complex can be utilized as a therapeutic drug at $200-400 \mu \mathrm{g} \cdot \mathrm{mL}^{-1}$

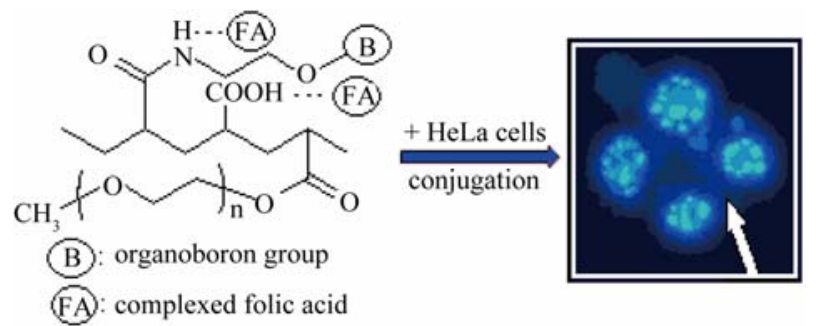

Scheme 2. Proposed structure of PAA...FA complex and conjugation with HeLa cells. concentration, where its toxicity was minimal for normal cells, but influential for cancer cells.

\subsection{Double Staining and Capase 3 Immune Staining results}

Apoptotic index was obtained by both double staining and caspase 3 immune staining methods. The results were presented in Table 2. If the cells treated by PAA-B at $400-650 \mu \mathrm{g} \cdot \mathrm{mL}^{-1}$ concentration, the number of apoptotic cells was not high. While PPA-B-PEO-F complex at $400 \mu \mathrm{g} \cdot \mathrm{mL}^{-1}$ concentration exhibits the highest apoptotic ratios on cancer cells. In addition, the number of apoptotic cells was high as well for the organoboron polymer/folic acid complex at $400 \mu \mathrm{g} \cdot \mathrm{mL}^{-1}$ concentration (Table 2). The results of light and fluorescent microscope investigation of the interaction of organoboron polymers with cancer cells were illustrated in Figure 7.

The cytoplasm's of apoptotic cells treated with complex were stained brown (Figure 7(b)) but, the cytoplasm of non apoptotic cells were not stained brown (Figure 7(a)). According to double staining results, apoptotic cells' nucleus stained bright blue and compartmentalized Figure 7(d)), but non-apoptotic cells' nuclei stained lifeless blue (Figure 7(c)). When the PEO-containing branched polymers applied, the number of apoptotic cells was decreased. However, the number of apoptotic cells was increased as $7 \%$ when they treated by PAA-PEO-B- F complex in $400 \mu \mathrm{g} \cdot \mathrm{mL}^{-1}$ concentration. Apoptotic index for Fibroblast cells was $18 \%$ at $400 \mu \mathrm{g} \cdot \mathrm{mL}^{-1}$ concentration of PAA-PEO-B-F. Moreover, there was no significant change on apoptotic index $(18 \%)$ of Fibroblast cell targeting by folic acid.

Apoptotic indexes in cancer and normal cells was estimated of caspase- 3 and double staining result. The important observations can be summarized as follows: we checked for apoptosis or necrosis with double staining (Hoechst 33342 and PI) and caspase 3 immune staining. It was observed that both the cytotoxicity and necrotic indexes of synthesized functional organoboron polymers

Table 2. The comparative analysis of apoptotic and necrotic HeLa cells index for (I) PAA, and its (II) organoboron amide (PAA-B), (III) PEO branched (PAA-B-PEO) and (IV) FA complexed (PAA-B-PEO-F) derivatives at $24 \mathrm{~h}$ incubation. Results are presented as means \pm SEM.

\begin{tabular}{ccccccccc}
\hline $\begin{array}{c}{[\text { Polymer] }} \\
\left(\mu \mathrm{g} \cdot \mathrm{mL}^{-1}\right)\end{array}$ & \multicolumn{4}{c}{ Apoptotic index (\%) } & \multicolumn{4}{c}{ Necrotic index (\%) } \\
\cline { 2 - 10 } & I & II & III & IV & I & II & III & IV \\
\hline 0 & $1 \pm 1$ & $1 \pm 1$ & $1 \pm 1$ & $1 \pm 1$ & $1 \pm 1$ & $1 \pm 1$ & $1 \pm 1$ & $1 \pm 1$ \\
100 & $5 \pm 1$ & $10 \pm 2$ & $12 \pm 2$ & $16 \pm 1$ & $2 \pm 1$ & $8 \pm 2$ & $2 \pm 1$ & $7 \pm 1$ \\
200 & $2 \pm 2$ & $16 \pm 2$ & $15 \pm 1$ & $20 \pm 1$ & $10 \pm 2$ & $25 \pm 3$ & $7 \pm 1$ & $18 \pm 2$ \\
400 & $5 \pm 1$ & $21 \pm 1$ & $18 \pm 2$ & $5 \pm 2$ & $24 \pm 2$ & $46 \pm 3$ & $20 \pm 1$ & $30 \pm 3$ \\
600 & $6 \pm 1$ & $6 \pm 1$ & $15 \pm 2$ & $20 \pm 1$ & $34 \pm 2$ & $53 \pm 3$ & $33 \pm 2$ & $45 \pm 2$ \\
\hline
\end{tabular}




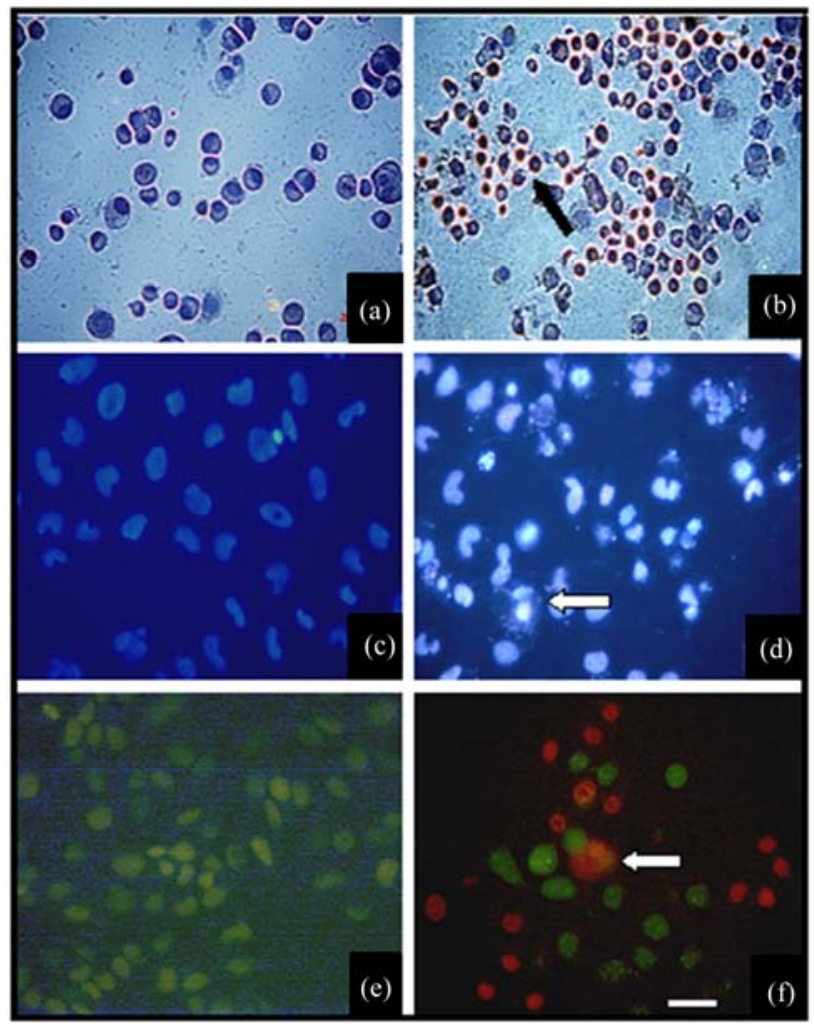

Figure 7. Light microscope images of (a) virgin (non-apoptotic) HeLa cells as a control group (stained with caspas-3 immune staining kit), and (b) $400 \mu \mathrm{g} \cdot \mathrm{mL}^{-1}$ concentration of organoboron polymer (PolyAC-B-2-PEO-F)/HeLa cells conjugate (stained with caspas-3 immune staining kit); (c) Fluorescent microscope image of nucleus of untreated HeLa cells (stained with Hoechst 33342 dye) as a control, (d) nucleus of HeLa cells (stained with Hoechst 33342); (e) Fluorescent microscope image of nucleus of untreated HeLa cells (stained with PI dye) as a control; (f) nucleus of HeLa cells (stained with PI dye); Photos (c) and (d) taken under DAPI filter, photos (e) and (f) taken under FITC filter. Figure (a) and (b) were recorded with $\times \mathbf{2 0 0}$ magnification. Figure (d), (e) and (f) were recorded with $\times 400$ magnification. Scale bar is $20 \mu \mathrm{m}$.

show approximately same values. The polymers with lower concentrations $\left(100-200 \mu \mathrm{g} \cdot \mathrm{mL}^{-1}\right)$ decrease in necrosis stained with PI dye. While the necrotic indexes of normal and cancer cells increase at relatively higher concentration $\left(400 \mu \mathrm{g} \cdot \mathrm{mL}^{-1}\right)$ of polymers, especially PAA-B (Table 2 and Figures 7(e) and (f)). However, when the polymer containing PEO was incubated to cancer cells, the necrotic index was decreased in cancer and normal cells.

Fluorescent microscope image of nucleus of untreated HeLa cells (stained with PI dye) as a control was presented in Figure 7(e), where formation of green spots indicates the nucleus of non-necrotic cells. Cancer cells exposed to polymer...FA complex became highly PI-positive. This observed fact indicated that the cells were undergoing to necrosis. HeLa and Fibroblast cells incorporated with PPA-B polymer provide a lysing the cell- membrane (necrosis) and relatively higher necrotic indexes $53 \%$ and $43 \%$ for the cancer and normal cells, respectively. When both the cells treated with PAAPEO-B-F copolymer, necrotic indexes decrease for HeLa (49\%) and Fibroblast cells (41\%).

\section{Conclusions}

This work presents the synthesis and characterization of organoboron, PEO branched and FA complexed derivatives of PPA and investigation of their antitumor activity (cytotoxicity, apoptotic and necrotic effects) toward HeLa and Fibroblast cells by using a combination of various biochemical, statistical and microscopy methods. It was observed that antitumor activity significantly depends on the structure, amount of ionizable free carboxylic groups, organoboron linkages and complexed fragments in the functionalized polymers, and changes in the following row: PAA $<<$ (PAA-B)s $<$ PPA-B-PEO $<$ PAA-B-PEO-F. Among them, PAA-B-PEO-F copolymer system showed promising antitumor activity against cancer cells through apoptosis and necrosis induced caspase-3-dependent partway. Apoptotic indexes in cancer and normal cells were estimated of caspase- 3 immune staining and double staining (Hoechst 33342 and PI) results. These observations are confirmed the realization of apoptosis and necrosis processes in the interaction of functionalized polymers with normal and cancer cells. Apoptotic index of cancer cells were obtained higher than normal cells. Especially, apoptotic effect of FA containing copolymer was increased compared with non-targeted copolymers. HeLa and Fibroblast cells incorporated with organobron polymer provide a lysing the cell-membrane (necrosis) and relatively higher necrotic indexes $53 \%$ and $43 \%$ for the cancer and normal cells, respectively. It was found that interactions of both the cells with PPA-PEO-B-F copolymer were decreased the necrotic indexes for HeLa (45\%) and Fibroblast cells (41\%). Utilization of this novel organoboron polymer as precursors in boron neutron capture therapy (BNCT) will be a subject for our future investigations.

\section{Acknowledgements}

The supports of this work by the TAEK (Turkish Atomic Energy Authority) and TÜBİTAK (Turkish Scientific and Technology Research Council) through TAEK-A3.H2.P2.01 and TBAG-2386 projects, respectively, are gratefully acknowledged. 


\section{REFERENCES}

[1] L. Seymour, "Synthetic Polymers with Intrinsic AntiCancer Activity," Journal of Bioactive and Compatible Polymers, Vol. 6, No. 2, 1991, pp. 178-216. doi:10.1177/088391159100600205

[2] J. Liao and R. M. Ottenbrite, "Controlled Drug Delivery: Challenges and Strategies," ACS, Washington DC, 1997.

[3] S. Akhtar, "Non-Viral Cancer Gene Therapy: Beyond Delivery," Gene Therapy, Vol. 13, No. 5, 2006, pp. 739740. doi:10.1038/sj.gt.3302692

[4] M. Dittgen, M. Durrani and K. Lehmann, "Acrylic Polymers. A Review of Pharmaceutical Applications," S. T. P. Pharma Science, Vol. 7, No. 6, 1997, pp. 403-437.

[5] M. Dimitrov, M. Lambovi, S. Shenkov, V. Dosseva and V. Y. Baranovski, "Hydrogels Based on the Chemically Crosslinked Polyacrylic Acid: Biopharmaceutical Characterization," Acta Pharmaceutica, Vol. 53, No. 1, 2003, pp. 25-31.

[6] W. Lee, T. G. Lee and W.-G. Koh, "Grafting of Poly(Acrylic Acid) on the Poly(Ethylene Glycol) Hydrogel Using Surface-Initiated Photopolymerization for Covalent Immobilization of Collagen," Industrial \& Engineering Chemistry Research, Vol. 13, No. 7, 2007, pp. 11951200.

[7] Y. Onuki, M. Nishikawa, M. Morishita and K. Takayama, "Development of Photocrosslinked Polyacrylic Acid Hydrogel as an Adhesive for Dermotological Patches: Involvement of Formulation Factors in Physical Properties and Pharmacological Effects," International Journal of Pharmacology, Vol. 349, No. 1-2, 2008, pp. 47-52. doi:10.1016/j.ijpharm.2007.07.021

[8] B. R. Saunders, H. M. Crowther and B. Vincent, "Poly[(methyl methacrylate)-co-(methacrylic acid)] Microgel particles: Swelling Control Using $\mathrm{pH}$, Cononsolvency, and Osmotic Deswelling," Macromolecules, Vol. 30, No. 3, 1997, pp. 482-487. doi:10.1021/ma961277f

[9] T. Sawai, S. Yamazaki, Y. Ikariyama and M. Aizawa, "pH-Responsive Swelling of the Ultrafine Microsphere," Macromolecules, Vol. 24, No. 8, 1991, pp. 2117-2118. doi: $10.1021 / \mathrm{ma} 00008 \mathrm{a} 067$

[10] S. Argentiere, L. Blasi, G. Ciccarella, G. Barbarella, R. Cingolani and G. Gigli, "Synthesis of Poly(Acrylic Acid) Nanogels and Application in Loading and Release of on Oligothiophene Fluorophore and Its Bovine Albumin Conjugate," Macromolecular Symposia, Vol. 281, No. 1, 2009, pp. 69-76. doi:10.1002/masy.200950709

[11] N. A. Petasis, "Expanding Roles for Organoboron Compounds-Versatile and Valuable Molecules for Synthetic, BIOLOGICal and Medicinal Chemistry," Australian Journal of Chemistry, Vol. 60, No. 11, 2007, pp. 795-798. doi:10.1071/CH07360

[12] W. Yang, S. Gao and B. Wang, "Boronic Acid Compounds as Potential Pharmaceutical Agents," Medicinal Research Reviews, Vol. 23, 2003, pp. 346-368. doi:10.1002/med.10043
[13] V. M. Dembitsky and M. Srebnik, "Synthesis and Biological Activity of $\alpha$-Aminoboronic Acid, Aminocarboranes and Their Derivatives," Tetrahedron, Vol. 59, No. 5, 2003, pp. 579-593. doi:10.1016/S0040-4020(02)01618-6

[14] P. G. Richardson, C. Mitsiades, T. Hideshima and K. C. Anderson, "Bortezomib: Proteasome Inhibition as an Effective Anticancer Therapy," Annual Review of Medicine, Vol. 57, 2006, pp. 33-47. doi:10.1146/annurev.med.57.042905.122625

[15] H. S. Ban, H. Minegishi, K. Shimizu, M. Maruyama, Y. Yasui and H. Nakamura, "Discovery of Carboranes as Inducers of 20S Proteasome Activity," Chemistry \& Medicinal Chemistry, Vol. 5, No. 8, 2010, pp. 1236-1241. doi:10.1002/cmdc.201000112

[16] C. Morin, "The Chemistry of Boron Analogues of Bio Molecules," Tetrahedron, Vol. 50, No. 44, 1994, pp. 12521-12569. doi:10.1016/S0040-4020(01)89389-3

[17] C. Baldock, G.-J. de Boer, J. B. Rafferty, A. R. Stuitje and D. W. Rice, "Mechanism of Action of Diazaborines," Biochemical Pharmacology, Vol. 55, No. 10, 1998, pp. 15411549 .

[18] A. Jabbour, D. Steinberg, V. M. Dembitsky, A. Moussaieff, B. Zaks and M. Srebnik, "Synthesis and Evaluation of Oxazaborolidines for Antibacterial Activity against Streptococcus Mutants," Journal of Medicinal Chemistry, Vol. 47, No. 10, 2004, pp. 2409-2410. doi:10.1021/jm049899b

[19] S. J. Benkovic, S. J. Baker, M. R. K. Alley, Y.-H. Woo, Y.-K. Zhang, T. Akama, W. Mao, J. Baboval, P. T. Ravi Rajagopalan, W. Wall, L. S. Kahng, A.Tavassoli and L. Shapiro, "Identitication of Borinic Esters as Inhibitors of Bacterial Cell Growth and Bacterial Methyltransferases, CcrM and MenH," Journal of Medicinal Chemistry, Vol. 48, No. 23, 2005, pp. 7468-7476. doi:10.1021/jm050676a

[20] S. J. Baker, Y.-K. Zhang, T. Akama, A. Lau, H. Zhou, V. Hernandez, W. Mao, M. R. K. Alley, V. Sanders and J. J. Plattner, "Discovery of a New Boron-Containing Antifungal Agent," Fluoro-1,3-dihydro-1-hydroxy-2,1-benzoxa-borole (AN2690), for the potential treatment of onychomycosis," Journal of Medicinal Chemistry, Vol. 49, No. 15, 2006, pp. 4447-4450. doi:10.1021/jm0603724

[21] H. B. Zhou, K. W. Nettles, J. B. Bruning, Y. Kim, A. Joachimiak, S. Sharma, K. E. Carlson, F. Stossi, B. S. Katzenellenbogen, G. L. Greene and J. A. Katzenellenbogen, "Elemental Isomerism: A Boron-Nitrogen Surrogate for a Carbon-Carbon Double Bond Increases the Chemical Diversity of Estrogen Receptor Ligands," Chemistry \& Biology, Vol. 14, No. 5, 2007, pp. 659-669. doi:10.1016/j.chembiol.2007.04.009

[22] J. F. Valliant, K. J. Guenther, A. S. King, P. Morel, P. Schaffer, O. O. Sogbein and K. A. Stephenson, "The Medical Chemistry of Carborones," Coordination Chemistry Reviews, Vol. 232, No. 1-2, 2002, pp. 173-230. doi:10.1016/S0010-8545(02)00087-5

[23] W. Chen, S. C. Mehta and D. R. Lu, "Selective Boron Drug Delivery to Brain Tumors for Boron Neutron Capture Therapy," Advanced Drug Delivery Reviews, Vol. 26, 
No. 2-3, 1997, pp. 231-247.

doi:10.1016/S0169-409X(97)00037-9

[24] F. Shosseler, F. Ilmain and S. J. Candau, "Structure and Properties of Partially Neutralized Poly(Acrylic Acid) Gels," Macromolecules, Vol. 24, No. 1, 1991, pp. 225234. doi:10.1021/ma00001a035

[25] M. Türk, Z. M. O. Rzayev and S. A. Khalilova, "Bioengineering Functional Copolymers. XIV. Synthesis and Interaction of Poly( $\mathrm{N}$-isopropyl Acrylamide-co-2,3-dihydro-2H-pyran-alt-maleic Anhydride)s with SCLC Cancer Cells," Bioorganic \& Medicinal Chemistry, Vol. 18, No. 22, 2010, pp. 7975-7984. doi:10.1016/j.bmc.2010.09.031

[26] Türk, Z. M. O. Rzayev and G. Kurucu, "Bioengineering
Functional Copolymers. XII. Interaction of Boron-Containing and PEO Branched Derivatives of Poly(MA-alt-MVE) with HeLa Cells," Health, Vol. 2, No. 1, 2010, pp. 51-61. doi:10.4236/health.2010.21009

[27] T. Shimisu and A. Minakata, "Effect of Divalent Cations on the Volume of a Maleic Acid Copolymer Gel Examined by Incorporating Lysozyme," European Polymer Journal, Vol. 38, No. 6, 2002, pp. 1113-1120. doi:10.1016/S0014-3057(01)00283-X

[28] O. Nobumichi and S. Shintaro, "Conformational Characterization of a Maleic Acid Copolymer with an Inflexible Side Chain," Journal of Macromolecular Science: Pure and Applied Chemistry, Vol. 27, No. 7, 1990, pp. 861-873. doi:10.1080/10601329008544810 